\title{
More than words?
}

\section{Conversation Analysis in Arts Marketing Research}

Terry O'Sullivan, Open University Business School, Michael Young Building,

Walton Hall, Milton Keynes MK7 6AA, United Kingdom, (Email:

t.j.osullivan@open.ac.uk)

Terry O'Sullivan is Senior Lecturer in Management at the Open University Business School.

Submission: October 2007

Revision: June 2008

Acceptance: June 2008 


\begin{abstract}
Purpose: To explore the use of Conversation Analysis methods in arts marketing research.
\end{abstract}

Method: Eight telephone interviews are conducted with members of the audience of a regional UK symphony orchestra who self-identified as users of online message boards ("web forums"). The interviews are transcribed and interpreted using techniques from Conversation Analysis (Wooffitt, 2001), an approach to qualitative data analysis which pays close attention to the details of language-in-use as a form of activity by and between speakers.

Findings: Conversation Analysis-led interpretation suggests that motivations for participation in web forums are more complex than literal analysis of interview data might reveal.

Conclusions: Conversation Analysis' detailed attention to how communicators manage their interaction emphasises the co-production of data between respondent and interviewer. The manner of emotion and meaning (re)construction through such exchanges provides valuable cues for researchers in interpreting respondent motivations. Because of the personalised nature of arts experience, this highly specific, context-oriented approach to understanding respondent meanings offers particular potential to arts marketing researchers.

Research limitations: The use of produced data (interview transcripts) rather than naturally-occurring data (spontaneous talk) in Conversation Analysis is controversial, but the article defends this choice.

Practical implications: Insights from Conversation Analysis enrich the interpretation of interview data to enhance qualitative research in the arts 
Originality and value of paper: Demonstrates the extra value scholars can leverage from qualitative data interpretation by Conversation Analysis, and thus adds to an understanding of arts consumers.

Keywords: Audience; web forum; classical music; Conversation Analysis.

Type of paper: Research Paper 


\section{More than words?}

\section{Conversation Analysis in Arts Marketing Research}

\section{Introduction and theoretical contribution}

This paper explores and illustrates the use of methods from conversation analysis (CA) in a specific arts marketing research context. Here the context is a research project using telephone interviews to investigate web forum use by members of the audience of UK symphony orchestras, but clearly the technique is extendable to many other enquiries involving qualitative interviewing. The argument of the paper is that the considerable investment of time and effort involved in using CA can yield worthwhile new perspectives on data, and thus insights into issues of interest to arts marketers, which might otherwise be unavailable. This introduction will attempt to define (or at least describe) CA and discuss the historical context of the development of this method, before arguing the appropriateness of applying CA to interview data in addition to naturally-occurring data.

$\mathrm{CA}$ is one of a number of methods that fall into the general category of discourse analysis, an approach to social research that looks for patterns in language in use (Taylor, 2001). The various varieties of discourse analysis share an emphasis on the constitutive and situated nature of language, opposing a commonsense view of language as simply reflective of reality, or separate from the social contexts which produce language. The focus of CA is on social context above all else - in fact the primary concern is to see language as an activity. Wooffitt (2001: 49) defines CA as "a method for the analysis of naturally occurring interaction" - specifically, how conversational talk is organised. Conversation in this sense is a generic term covering any kind of talk, whether informal (such as a group of neighbours talking about cars) 
or institutional (such as an encounter between a doctor and a patient, or a teacher and a class). A group of American sociologists developed CA in the 1960s and 1970s (Harvey Sacks, Gail Jefferson and Emmanuel Shegloff) in order to analyse how people construct a common-sense social reality through the business of performing everyday life, in the tradition of Garfinkel (1967) and "ethnomethodology" (literally "people method"). Ethnomethodology grounds sociological analysis on actual instances of behavior rather than the more distancing methods of laboratory experiments or researcher-led accounts. The choice of recorded examples of conversation as data results from the convenience and accessibility of such data sources, rather than from any intrinsic commitment to textual data on the part of the researchers. It could be any other form of observable interactive behavior, but it happens to be conversation because that was what was available and met the researchers' needs for close and repeated scrutiny (Wooffitt, 2001: 50). A further advantage of this kind of data is that different researchers can conveniently share and re-analyse the data sets. This tradition continues in the way that scholars publishing work using CA often make their data recordings available directly online as well as through transcribed excerpts in printed articles (e.g. Llewllyn, 2008).

It is important to keep the behavioral focus of CA in mind when seeking to apply its techniques to wider contexts such as arts marketing research. Heritage (2001: 45) emphasises CA is about what people do in conversation rather than the content of what they say, arguing that it is "a method for studying social interaction. It is not designed for the analysis of texts, or of contexts where activities are progressed by means other than social interaction. Instead it is a method designed to unpack the fundamental organization of social action and interaction, and in its applied and institutional aspects, to link empirical findings about the organization of action and 
interaction to other characteristics of social actors and the settings they act in." But, while accepting Heritage's caveat about the proper focus of the method being on social interaction rather than textual analysis, the author argues that the interpretive value of CA is actually revealed through the unpacking and linking of people's interaction in talk to their other characteristics (such as consumer motivation). CA's detailed attention to the strategies of communicative interaction unlocks layers of meaning which would be unavailable from studying textual content alone. As Antaki (n.d.) writes in an online tutorial about CA, "What it has accumulated as insights and findings can be brought to bear on any set of data where language is used in interaction. Its cross-light shows up subtleties in the terrain which are invisible from a more 'common-sensical', straight-down perspective."

Ethnomethodology demonstrates how everyday behavior is subject to rules the actors assume more or less unconsciously. When it comes to behavior involving talk, these rules cover not only the appropriate arrangement of words through grammar and pronunciation, but the appropriate social arrangement of speakers through conventions such as turn-taking in a conversation (i.e. knowing when to start or stop talking so that the conversation can progress among a number of speakers). CA reveals how speakers' manipulation of such rules can achieve particular objectives in communicative interaction alongside the literal content of the conversation. Events such as interruptions, discontinuities and verbal patternings establish and sustain hierarchical relations between speakers, which then create, support and occasionally subvert patterns of meaning in their interaction.

In summary, CA allows researchers to understand conversations (including for the purposes of this article the special kind of conversations known as qualitative interviews) as sequences of actions that participants perform to create and manage 
meaning between themselves. In particular, CA focuses on how participants in a conversation anticipate and qualify each other's semiotic opportunities. Rather than seeing talk as a transparent medium for the intentional transmission of pre-existing ideas from one speaker to another, CA reveals how the organisation of talk generates and disciplines what meanings are possible. Every utterance in a conversation (or an interview) reflects prior utterances, and sets the scene for what can meaningfully follow. As Heritage (1984: 242) states, "the significance of any speaker's communicative action is doubly contextual in being both context-shaped and contextrenewing", (original italics, cited by Titscher, et al, 2000: 108). CA understands the conceptual content of what people say as an "occasioned phenomenon" (Edwards, 1997: 86, italics in original) where position in an interactive sequence drives meaning.

How does (or can) this interaction-occasioned understanding of content apply to interview data rather than to naturally-occurring conversations? Traditionally conversation analysts eschew data from experimental procedures or interviews in favour of found data (whether informal or institutional) such as broadcast interviews, recorded telephone conversations, or transcripts of therapy sessions (cf. respectively Wetherell, 2001; Sacks, 1992; Silverman, 1997a). Edwards (1997, p. 89) argues for a more inclusive (and reflexive) approach to what is acceptable as data. His key principle is that "[a]ny interactional phenomenon can be naturalised by treating it as natural" (italics in the original). Thus when understood as an interaction rather than an instrument an interview becomes legitimate data for analysis. Indeed, CA directs the researcher to "be interested in what you've got" (Sacks, 1992, cited by Edwards, 1997, p. 89) - in other words to start from what the data presents rather than from predetermined assumptions about what the data should contain or mean. This starting point opens up fresh possibilities of understanding what interview data can offer (in 
the same way that ethnography considers the setting of an interview as seriously as its verbal content (Hammersley and Atkinson, 1995, p. 141)).

Of course such a starting point also problematises the role of the interviewer/researcher if, as in this project, the same individual carries out both functions. As analyst, one needs to approach one's own contribution to the data afresh. Here, interest in what you've got means interest in a recording and a transcript and approaching these as far as possible without prejudice; rediscovering and reframing one's own words spoken in a particular, and remembered, social, cognitive and affective interactive context. It quickly becomes apparent that, while lacking the spontaneity of everyday conversation, the interactive sequence of an interview is far richer, more complex and more unpredictable than merely a predetermined question prompting an answer, followed by another question. Interviews draw on the conventions of any verbal social interaction - not only speech itself but pauses, nonverbal gestures (both visible and audible), intonation, pace, and breathing, to name but the most immediately obvious. Indeed, one of the most exciting aspects of bringing a CA perspective to qualitative interview data is the way $\mathrm{CA}$ forces the interviewer to confront the inevitability of interactive structure, revealing the interviewer's reciprocal role in the production of meaning with the respondent. Viewed in this light the interviewer becomes less an objective extractor of ideas and opinions, more a catalyst and collaborator in their production.

Far from invalidating the resulting data against some chimerical standard of objectivity, acknowledging the interviewer's presence in the data promotes a healthy reflexivity in research, which is peculiarly appropriate to the challenge of understanding arts consumption. Perhaps more than most sectors, the arts feature producers and marketers who are themselves steeped in consumption of the product 
and are committed to proselytising on the product's behalf. In turn, complex themes of social distinction and identity work quite independent of the visible act of attendance at an opera or visit to a gallery infuse arts marketing (cf. Gainer, 1995; Slater, 2007). Arts marketing research is thus even less likely to be a disinterested, allegedly objective process than social research in general. CA compels the researcher to admit his or her presence in the creation of the data, with all the richness of meaning, and political complexity, which that entails.

Acknowledging that the interactive detail of an interview occasions the phenomenon of meaning affords the researcher richer material than would be available from the same data divorced from the production context. In particular, the subtleties of subjective human experience, brought into consciousness and articulated within a research interview in ways which might not occur in any other setting, are inseparable from the verbal context used to recall them. This is of clear interest to marketers exploring aesthetic and emotional experience. The theoretical contribution of this paper is, therefore, to encourage researchers in the field of arts marketing to make judicious but creative use of an analytical methodology which, while wellestablished in other areas of the social sciences (Nielsen and Wagner, 2007), has yet to make an impact on how marketers understand the motivations and behavior of arts consumers. The very subjectivity, unpredictability and personal emotion associated with arts experience makes the phenomenological stance of CA a highly appropriate methodology.

\section{Principles of Conversation Analysis}

Phenomenology, from which CA is a methodological descendant, dismisses the idea of an objective world against which researchers can validate subjective 
experience. Instead, phenomenology argues that "there are no hard facts, only interpretations - that facts are intersubjectively constructed." (Smith, 1998: 164). Intersubjectivity - a term Schutz (1967) coins to describe the way in which individuals are able to participate in each other's consciousness of the world through communicative action - is what CA seeks to bring to light. Performing language in a social context (including the context of a qualitative interview) is not just a way of reporting experience, but actively (re)constituting experience. As Smith (1998: 164) puts it: "..the act of describing experience actually creates the object of analysis."

CA has a technical vocabulary that names specific procedures employed by speakers (or "members" of conversations/society) in conversational interaction. The author names and explains several of these procedures later in this article in the process of analysing selected data extracts. But CA has a further set of terms for the ways in which participants intersubjectively share their consciousness of the world as a result of their interactions. One such term is "member categorization devices" (MCDs) - the way in which conversation members establish the identity of what they are referring to. Schegloff (2007: 467) describes MCDs as "an apparatus", consisting of categories (such as opera, theatre or dance) and collections to which such categories belong (such as performing arts), as well as rules of application.

How MCDs work can be illustrated by taking a simple verbal sequence such as "The baby cried. The mommy picked it up" (Sacks, 1972). People immediately understand from the context that the mommy here is the mother of the child, and that the crying has something to do with the picking up. But how does this act of identification (or the myriad others which everyday conversation entails and necessitates) come about? There is no information about either fact in the story itself. Sacks offers an explanation of what is going on in this kind of sense-making through 
the concepts of collections (here the family) and categories (here the mommy and baby), and the fact that certain types of activity (such as picking up crying babies) are associated with the behavior expected from certain categories - what CA terms category-bound activities (CBAs). Sacks further points out that interlocutors tend to be consistent in their ascription of categories to particular collections (hence the mommy/baby assumption above), and that speakers need only refer to one category characteristic for others to understand what collection it relates to. Shegloff (2007: 471) refers to these principles respectively as consistency and efficiency

This brief account of membership categorisation devices and category-bound activities may seem somewhat abstract out of context, but the strength of these notions become clear when conducting detailed analysis of interview data. MCDs and CBAs are particularly relevant to the subtle ways in which respondents (and interviewers) either acknowledge or disavow what they see as the behaviors and positions that interview questions imply. In the case of the project drawn on for this article, such member categories include interviewer, respondent, web forum (message board) user, audience member, musician, expert, enthusiast, and so on. Consider the following exchange, (Figure 1) where $\mathrm{T}$ is the interviewer and $\mathrm{R}$ the respondent:

Figure 1 here

The conventions of transcription for CA may look confusing to readers who are unfamiliar with them (and the author will be discussing the issue of transcription in more detail later in this article). The reader may find it useful to consult Extract 1(b) (Figure 2) later in this article as a more traditional form of transcription of the same data and refer back. However in Extract 1(a) (Figure 1) the transcription conveys enough detail to document a member categorization device in action. The line numbers provide a convenient reference. The interviewer's opening gambit, with the 
repeated "you" and a self-interruption "eh" filled simultaneously with the response "yeh" from the respondent at line 2 (overlapping speech is marked by square brackets in this transcription format) displays some tentativeness around linking a questionnaire response to an occasional behavior (here, being a message board contributor). The hesitations achieve a position for the interviewer of appearing to be open to evidence and allowing the respondent to confirm her behavior. They contribute to what Potter (1997) calls "stake inoculation" on the part of the interviewer - the disavowal of a vested interest or motive which might compromise one's ability to appear authoritative or persuasive (Wetherell, 2001: 21). In this situation the stake is the interviewer's vested interest in the convenient (but possibly inappropriate) categorisation of the respondent. The simultaneous "yeh" from the respondent is a way of managing the continuation of this tentative opening in a way which confirms the legitimacy of its development.

Pauses of a fifth of a second or more in interaction are very noticeable and the transcription indicates these by a decimal figure in brackets. The pause of 0.2 of a second from the respondent before replying is typical of what CA calls a "dispreferred" response. Refusals, in general, are dispreferred responses - in other words, they are more troublesome to speakers than acceptances or agreements. They are usually more awkwardly constructed (as here) than acceptances, which are a great deal smoother and facilitative of conversational flow. Usually speakers accompany refusals or denials with verbal formulae which achieve some kind of mitigation of the disturbance they create. At line 5, the respondent mitigates her refusal to be categorised as a message board user, following the pause, by acknowledging that it might have been true of her in the past, but has now "gone by the board" (an interesting choice of words considering the interviewer's use of "board" to denote 
forum, and perhaps a further gesture of mitigation through appropriating the interviewer's vocabulary).

How does this examination of the interactive aspects of what is a very brief piece of data (no more than six seconds of recording) enhance our understanding of the text it presents? The member categorisation processes at work include the interviewer's establishment of a professional, objective persona for himself, in tension with the natural conversational self, facing uncertainty and an unfamiliar interlocutor in the context of a telephone interview. The respondent, anxious not to be categorised inappropriately as a current web forum user (although this disavowal was not entirely ingenuous according to later material in the interview) refuses to let the categorybound activity implied in the question fix her. She is at pains to position her identity as more complex and ambiguous than the category will allow - revealing something about her attitude to web forum use which, although not explicit in what she has to say about her own behavior, is an important and significant backdrop to understanding it. One of the conclusions drawn from this interview, consistent with others in the project, is that posting on web forums is something respondents associate with other people rather than readily acknowledge as part of their own repertoire of behavior, and perhaps also associate with complex negative feelings.

Heritage (1997) suggests that there are at least two kinds of CA research: “The first examines the institution of interaction as an entity in its own right; the second studies the management of social institutions in interaction" (original italics, p.162, cited by ten Have, 1999, p. 8). As evident from the preceding analysis of Extract 1(a), these two kinds of research are difficult to disentangle in practice. The data present interaction in its own right (here telephone interviewing), analysis of which leads to an understanding of how the relative subject positions of researcher and respondent 
(as social institutions) are "talked into being" in Heritage's memorable phrase, around the particular context of the research question. It is to this question that we will now turn.

\section{Research Context of the Study}

The site of the research was the XY Symphony Orchestra (XYSO), a performing arts organisation with a strong commitment to access, education and audience development. The organisation's website embodies this commitment. As well as programme information and booking facilities, the site hosts podcasts and material directed at inexperienced concertgoers (such as explanations and audio clips of current repertoire). A web forum for audience interaction complements the access strategy (topics include ticket pricing, personal reviews of performances and questions for the performers and staff). But very low perceived levels of activity have called the web forum's relevance into question. Is the web forum contributing to the access strategy in any meaningful sense? Or is it undermining access by creating an impression of a small coterie of insiders rather than an open forum? The research project aimed to discover the barriers and incentives to web forum use by talking to relevant audience members.

The author conducted eight telephone interviews with audience members who had self-identified as web forum users (though not necessarily active on the XYSO forum). The number of interviews represents what was feasible within the time and resources available for the project, and takes into account refusals from, and failures to reach, the full number of web forum users identified from the recruitment questionnaire. This was an online questionnaire yielding information about demographic and behavioral characteristics including web use. The XYSO distributed 
this via a link embedded in an email newsletter to regular audience members. Only 16 of the 106 usable responses to the recruitment instrument indicated web forum use.

This figure (approximately $15 \%$ of the responses to the recruitment instrument) suggests that web forum use is a minority activity even amongst audiences habituated to receiving information online (the sampling frame was an email list). Small sample size is a characteristic of any attempt to study an emerging phenomenon, but is appropriate (because of the likelihood of a restricted size data set) for methods of close data analysis. CA presents itself as an appropriate method in this context.

A potential limitation is that telephone interviewing as a way of exploring motivations for web forum use may not be congenial to respondents whose preferences evidently include remote, asynchronous communication. One objection might be that hesitations and inconsistencies in the interviews result not from, for example, reluctance to be categorised by implication (as in Extract 1(a) (Figure 1)) but from discomfort with the synchronicity of the telephone compared to the ability to consider and edit online messages which characterises web forum use. However, web forums are only one of the many ways in which people communicate, and (judging from the interviews) represent only a tiny proportion of even the most dedicated users' communication activity. Thus the conversational discontinuities so important to $\mathrm{CA}$ as material are far more likely to arise from a struggle to articulate meaning than from discomfort with the telephone in this study.

\section{Examples from the Study}

Wooffitt (2001: 58) admits that it is difficult to establish a specific set of procedures for carrying out CA research: "unlike the set methods for conducting certain kinds of statistical analyses, there is no "recipe" for doing conversation 
analysis". However, all CA research begins with the extremely close scrutiny of data and its detailed formal description. This leads inevitably to the issue of recording and transcription, already broached in the preceding discussion of Extract 1(a) (Figure 1). The best-known system of the several CA uses is that devised by Gail Jefferson in the 1970s (Taylor, 2001). The symbols and format used enable the user to access details essential to understanding what is going on in an interaction, in ways which stress the social, embodied nature of language. With a little practice, they are relatively simple to understand and use.

Comparing a standard transcription to a Jeffersonian transcription provides the most dramatic illustration of the gain in data from using Jefferson's system.

Continuing the data already seen in Extract 1(a) (Figure 1), Extract 1(b) (Figure 2) presents the data as it might appear in a standard transcription. Extract 1(c) (Figure 3) maintains the level of detail begun in Extract 1(a) (Figure 1). As throughout when quoting data in this article, $\mathrm{T}$ is the interviewer, $\mathrm{R}$ the respondent and the author has changed all names (including those of performers).

Figure 2 here.

Extract 1(b) (Figure 2) cleans up the hesitations, false starts, non-verbal utterances and repetition which we have seen as significant in the same data transcribed as Extract 1(a) (Figure 1). The interviewer comes across as confident rather than tentative, the respondent as candid and straightforward. Her final statement reads like a clarification of consistent and (from a research point of view) unproblematic behavior. With data having more detail, a more complex picture emerges (Figure 3). 
Figure 3 here

As already discussed, this respondent is careful to qualify the impression of her use of web forums not only through explicit disavowal of current involvement, but also through her pause before responding to the interviewer's first statement (lines $1-4)$. The pause lasts 0.2 seconds as shown. The sign (.) as at line 8 represents any noticeable pause of less than 0.2 seconds. The interviewer's opening statement acts as the first part of what CA terms an adjacency pair - a sequence of two utterances adjacent to one another in a sequence of conversation, where the second part is contingent on the first in the way it produces meaning (Heritage, 1984, cit. Wooffitt, 2001: 53). The first part of the adjacency pair here assumes, albeit tentatively, that the behavior mentioned (contribution to message boards) will be confirmed in the response. The pause that follows, and the complexity of the answer, is a speech act which, as we have seen, the respondent uses to mitigate her rejection of this assumption.

This leads, after a false start, to an account of her actual online behavior (focusing on an international popular singing star rather than the XYSO, and on "checking up" rather than "contributing"). The respondent's choice of words continues her process of qualification of the activity assumed in the interviewer's opening statement. Note here the offer of a different term "what we call a forum" for "online message boards" in the subsequent account of her behavior. The underlining in "forum" indicates emphasis on a word or syllable, here performing the function of differentiating the word emphatically from the interviewer's earlier term and establishing an independent world of meaning over which the respondent is asserting control.

The overall effect is that of attempted minimisation ("I might er contribute some comment or something”) suggesting a studied casualness, associated with 
ambivalence about spending time online. This issue of time is given further prominence in the enactment of the phrase " $>$ I'm, I mean I'm more busy these days $<$ " where the chevron marks at either end of the words denote the acceleration and slowing down of speech relative to adjacent words it in a transcript.

This transcript reveals many other significant details missing from Extract 1(b), which might take the researcher in a variety of directions of interpretation: the false starts at lines 8 and 9 where the interviewer and respondent seem unable temporarily to get on each other's wavelength (perhaps as a result of the interviewer trying to reassert control of the direction of the interview); the dog barking at line 15 (intruding the respondent's actual world of distractions and other concerns into the data); and, also at line 15 into 16, the respondent's hesitation and then qualification of "webs (mm), on his official website" (positioning her as a discerning and selective user of such resources). Words or letters in brackets like “( $\mathrm{mm})$ " here indicate an unclear fragment in the recording. However, the most important theme which emerges remains that of ambivalence about time - not having enough time to be a web forum user, having been one in the past, but nevertheless continuing to be one in the present (in a selective and discerning way, implying that enough time is available if used judiciously).

Other respondents echoed this conflicted position regarding time, suggesting time poverty as a major demotivator from posting on web forums. Another respondent (Figure 4) emphasised perceived lack of expertise rather than time as a reason for preferring reading to posting messages.

Figure 4 here. 
In spite of being a life-long concertgoer, this respondent was diffident about discussing music either online or face-to-face. Instead he uses reviews and accounts from web forums (including the XYSO forum) as comparators for his own experiences. His sentence explaining this ("Err looking at what other people...etc.", lines 1 - 4) takes a three-part list form familiar in CA (Heritage \& Greatbatch, 1986). Three-part lists carry a culminative finality (which another speaker often receives as a cue to take the next turn in a conversation). Here the form achieves an emphatic statement about the general grounds on which one might evaluate a performance; but a less formal passage where the speaker positions himself as inexpert about "the fine details" (a phrase which recurred in the interview as an index of the level of expertise of online discussants) follows.

Interestingly, there is some turbulence (i.e. verbal disturbance) accompanying this contextualisation of the appreciation of a performance in a social milieu. Lines $4-5$ feature a noticeable pause, and a false start and then continuation (known as a "selfrepair" in CA, as opposed to repairs offered by others who correct speakers they hear erring in fact or terminology) as the respondent talks about the kind of discussion he might have in real life with concert-going companions. Line 6 features an encouraging interjection from the interviewer to help manage this awkwardness, followed by the respondent's attempt to disavow membership of the category "fanatic for music" within the collection of concertgoers talking about a performance. The lengthening of the vowel (denoted by the colon) in line 7 in the indefinite article "a:ah" enacts his reluctance to be associated with the category. The simultaneous laughter from the interviewer and further disavowal of expertise from the respondent at lines 8 and 9 acknowledge the distinctions of expertise and taste which are part of 
the social complexity of musical experience, yet which remain for many an insidious barrier to its comfortable appropriation.

Allied to the anxieties of time and expertise is the further issue of social risk in online encounters because of their potential for realisation face to face. Another respondent (Figure 5) talked about the difference between meeting someone online and then going to a concert together in the real world (a likely scenario in relation to forums discussing the performing arts):

Figure 5 here

The dissonant organisation of language in the extract accentuates the dissonance between the online and real-life personae. The speaker begins by claiming that people appear flat online, but fill out when met in real life (lines 1 and 2). Yet the disappointing encounter in question turns out to be with someone who is much flatter in real life ("a drunkard and (.) quite rude actually", line 13) than in his "thought provoking" and "interesting" online persona. Hesitations and repairs are typical of the way in which speakers construct delicate objects in talk (in this case an individual displaying challenging behavior, which might cast doubt on the competence of the speaker as judge of character) (Silverman, 1997a). The interviewer uses laughter (possibly injudiciously) both here (line 10) and in Extract 2 to smooth a potentially delicate transition about social embarrassment. The respondent also invokes laughter at line 13 in self-deprecation. The effect is to establish himself as surviving this illjudged social encounter with his credentials as a judge of character intact.

The organisation of language in this extract, as much if not more than its literal content, implies that people perform personalities inconsistently online and offline, but also that one performance has no more claim to final authenticity than another. As with the findings about time poverty and lack of expertise evident from Extracts 1 and 
2, using CA reveals complexities which enhance the findings about social risk available from the data. The enhanced understanding to which the close analysis of the data gives access is not just an academic point. There are clear practice implications in each of these findings for how arts organisations might want to manage their online presence more effectively to combat issues around time, confidence and risk.

\section{Summary and Outlook}

To conclude, consider two potential objections to CA (the first CA's disregard for evidence outwith the data, the second CA's obsession with form rather than content) and offer a final commendation of the usefulness of CA to the arts marketing researcher.

CA invites researchers to take the materials of a conversational interaction, rather than external considerations and presuppositions, as sufficient to develop an understanding of what is happening between speakers. Researchers could, however, argue that the behaviors to which they are paying such close attention have origins outside the immediate material of the conversations. For example Croft, Boddy and Pentucci (2007) offer a salutary reflection on the gendered nature of communication in any research interview. They argue that groups of men speak differently from groups of women, men preferring emphatic statements, women preferring debate (often around emotions). Such differences in behavior, might lead to interactive phenomena which are less about the immediate circumstances of the interview (e.g. repairs and turbulence around the construction of delicate objects) and more reflective of the gender of the participants (e.g. a female respondent behaving cautiously in conversation around an emotional subject in a way which suggests consideration of 
different aspects of the issue). Certainly, an interviewer, male in this case, needs to be sensitive to the potentially different meanings which arise from whether his interlocutor is behaving as a male (as in Extracts 2 and 3) or female (as in Extract 1). In fact CA directs the researcher to see how the interaction constructs maleness or femaleness, a category (man, woman) within a collection (gender) substantiated by category-bound activities that members understand and share. The ethnomethodology underlying CA needs to acknowledge local variation between genders and cultures just as much, say, as between face to face and telephone interviewing. Indeed CA's fundamental precept, noted earlier in this article, to "be interested in what you've got" should guide the analyst to discover what rules are implicit in the data in each case, rather than bringing a ready-made set of assumptions to bear.

A second potential objection to $\mathrm{CA}$ is the insistence on analysing interviews as interactions, rather than as content. To researchers schooled in textual analysis this can seem perverse as a way of getting more out of qualitative data -- a case of determinedly staring at the trees when the woods are what counts. But the fact is that, for qualitative researchers, interview data demand detailed attention to both form and content, even though content gets the lion's share of attention in most qualitative work. Co-opting techniques from CA, even if a researcher stops short of the entire epistemological commitment the approach implies, is a useful corrective and, as this article argues, pays dividends in adding value to interpretation.

In the research project drawn on in this article, as in any other, the researcher constructs a sample to represent something beyond itself, drawing on resources such as secondary data to establish the characteristics of the population of interest, choosing a sampling frame and arriving at a sample of a particular size. Interviews take place with as many cases as can be reached and will agree. Particularly in 
ethnographic research, other sources of data may play an important role in triangulating what is available from the interview and setting the context, but the interviews are the justification for this triangulation. The data they present are like a narrow window through which the researcher strains to catch a glimpse of the world beyond. But, as with the car window Barthes (1973) invokes in his essay on myth, research attention can be directed at both seeing the surface of the data (looking at the window, rather like CA looks at the interaction) and looking through the surface (window) to see the landscape (rather like more traditional approaches to qualitative data analysis).

The problem is that the latter approach can encourage the notion that there is an objective landscape beyond the window which one could see better were the window larger, or clearer. In contrast, the phenomenological principle that reality is based in experience rather than floating independently in some essential and pristine form underlies CA. CA insists that the window is all researchers have, but that this is sufficient. Reality is locally produced, in conversational interaction (or, as here, in interviews), and the researcher needs to attend to the detail of how this interaction happens in order to understand the way that respondents construct their worlds.

Using CA is labour intensive, both in terms of basic activities such as transcription, and in getting to grips with the terminology, assumptions, principles and implications. Finally, then, why should an arts marketing researcher be troubled to consider using CA? This article provides some convincing instances of where CA has enriched the interpretation of data in a particular research context. More generally, by insisting the researcher dismiss preconceptions about data (hard though it be to avoid hypothesising) and attend to the interactions that data present, CA encourages that essential research attribute: an open mind. $\mathrm{CA}$ is a corrective to the temptation for the 
evidence to confirm one's prejudices, an invitation to think differently and to see new and authentic things. With an orientation to how specific individuals make sense of, and share, their contingent realities, $\mathrm{CA}$ is peculiarly appropriate for researching the very precisely situated experiences in which arts patrons participate. 


\section{References}

Antaki, C. (n.d.), “An Introductory Tutorial in Conversation Analysis,” Available online at: http://www-staff.lboro.ac.uk/ ssca1/intro1.htm [Accessed 30th May 2008]

Barthes, R. (1973), "Myth today", in Barthes, R., Mythologies, Paladin, London, pp. $109-143$.

Croft, R., Boddy, C. and Pentucci, C. (2007), "Mean What You Say, Say What You Mean”, International Journal of Market Research, Vol. 49 No. 6, pp. 715 734.

Edwards, D. (1997), Discourse and Cognition, Sage, London.

Gainer, B. (1995), "Rituals and Relationships: Interpersonal Influences on Shared Consumption", Journal of Business Research, Vol. 32, pp. 253 - 260.

Garfinkel, H. (1967), Studies in Ethnomethodology, Prentice-Hall, Englewood Cliffs, N.J

Hammersley, M. and Atkinson, P. (1995), Ethnography Principles in Practice, $2^{\text {nd }}$ edition, Routledge, London.

Heritage, J. (1984), Garfinkel and Ethnomethodology, Polity Press, Cambridge. 
Heritage, J. (1997), “Conversational Analysis and Institutional Talk: Analysing Data" in Silverman, D. (Ed.), Qualitative Research: Theory, Method and Practice, Sage, London, pp. $161-82$.

Heritage, J. \& Greatbatch, D (1986), “Generating Applause: A Study of Rhetoric at Party Political Conferences", American Journal of Sociology, Vol. 92 No. 1/July, pp. $110-157$.

Heritage, J. (2001), "Goffman, Garfinkel and Conversation Analysis”, in Wetherell, M., Taylor, S. and Yates, S. J. (Eds.), Discourse Theory and Practice: A Reader, Sage with the Open University, London, pp. 47 - 56.

Llwellyn, N. (2008), “Organization in Actual Episodes of Work: Harvey Sacks and Organization Studies”, Organization Studies, Vol. 29 No. 5, pp. 763 - 791.

Neilsen, M. F. and Wagner, J. (2007) "Guest Editorial: Diversity and Continuity in Conversation Analysis", Journal of Pragmatics, Vol. 39, pp. 441- 444.

Potter, J. (1997), “Discourse Analysis as a Way of Analysing Naturally-occurring Talk", in Silverman, D. (Ed.), Qualitative research: theory, method and practice, Sage, London, pp. $144-160$.. 
Sacks, H. (1972), "On the analysability of stories by children” in Gumperz, J.J. and Hymes, D. (Eds.), Directions in Sociolinguistics, Holt, Rhinehart and Winston, New York, pp. $325-345$.

Sacks, H. (1992), "Lecture 1: Rules of Conversational Sequence”, in Jefferson, G. (Ed.), Lectures on Conversation, Blackwell, Oxford.

Shegloff, E.A. (2007), “A Tutorial on Membership Categorization”, Journal of Pragmatics Vol. 39. No. 3, pp. $462-482$.

Silverman, D. (1997a), "The Construction of Delicate Objects in Counselling”, in Wetherell, M., Taylor, S. \& Yates, S. J. (Eds.), Discourse Theory and Practice: A Reader, Sage with the Open University, London, pp. 119 - 137.

Silverman, D., (Ed.), (1997b), Qualitative Research: Theory, Method and Practice, Sage, London.

Silverman, D. (2001), Interpreting Qualitative Data: Methods for Analysing, Talk, Text and Interaction, $2^{\text {nd }}$ edition, Sage Publications, London.

Slater, A. (2007), "Escaping to the Gallery: Understanding the Motivations of Visitors to Galleries", International Journal of Non profit and Voluntary Sector Marketing, Vol. 12, pp. 149 - 162. 
Smith, M.J. (1998), Social Science in Question, Sage with the Open University, London.

Taylor, S. (2001), “Locating and Conducting Discourse Analytic Research”, in Wetherell, M., Taylor, S. \& Yates, S. J. (Eds.), Discourse as Data: A Guide for Analysis, Sage with the Open University, London, pp. 5 - 48.

Taylor, S. (Ed.), (2002), Ethnographic Research A Reader, Sage Publications with the Open University, London

ten Have, P. (1998), Doing Conversation Analysis, Sage Publications, London.

Titscher, S., Meyer, M., Wodak, R. and Vetter, E. (2000), Methods of Text and Discourse Analysis (translated by Bryan Jenner), Sage Publications. London.

Wetherell, M. (2001), “Themes in Discourse Research: The Case of Diana”, in Wetherell, M., Taylor, S. \& Yates, S. J. (Eds.), Discourse Theory and Practice: A Reader, Sage with the Open University, London, pp.14 - 28.

Wetherell, M., Taylor, S. \& Yates, S. J. (Eds.), (2001a), Discourse as Data: A Guide for Analysis, Sage with the Open University, London.

Wetherell, M., Taylor, S. \& Yates, S. J. (Eds.), (2001b), Discourse Theory and Practice: A Reader, Sage with the Open University, London. 
Wooffitt, R. (2001), "Researching Psychic Practitioners: Conversation Analysis", in Wetherell, M., Taylor, S. \& Yates, S. J. (Eds.), Discourse as Data: A Guide for Analysis, Sage with the Open University, London, pp. 49 - 92. 
Figure 1: $\quad$ Extract 1(a)

$1 \quad \mathbf{T} \quad$ You, you mentioned [eh]

$2 \quad \mathbf{R} \quad$ [yeh]

3 T in your response to the questionnaire that you occasionally

$4 \quad$ contribute to online message boards about music

$5 \quad \mathbf{R} \quad$ (0.2) Ah. I did in the past but that's, that's gone by the board

\section{Figure 2: $\quad$ Extract 1(b)}

T: You mentioned in your response to the questionnaire that you occasionally contribute to online message boards about music.

R: I did in the past but that's gone by the board, because I'm more busy these days. I just don't have much time for that.

T: I can appreciate that.

R: I was just going to say that the only one that I might contribute to what we call a forum occasionally, is I'm an ardent Tony Bennett fan and I regularly check up on his official website, and I might contribute some comment or something to the forum on there.

\section{Figure 3: $\quad$ Extract 1(c)}

$1 \quad \mathbf{T} \quad$ You, you mentioned [eh]

$2 \quad \mathbf{R} \quad$ [yeh]

$3 \mathbf{T}$ in your response to the questionnaire that you occasionally

4 contribute to online message boards about music

$5 \quad \mathbf{R}$ (0.2) Ah. I did in the past but that's, that's gone by the board

6 because $>$ I'm, I mean I'm more busy these days $<$ I just don't have 


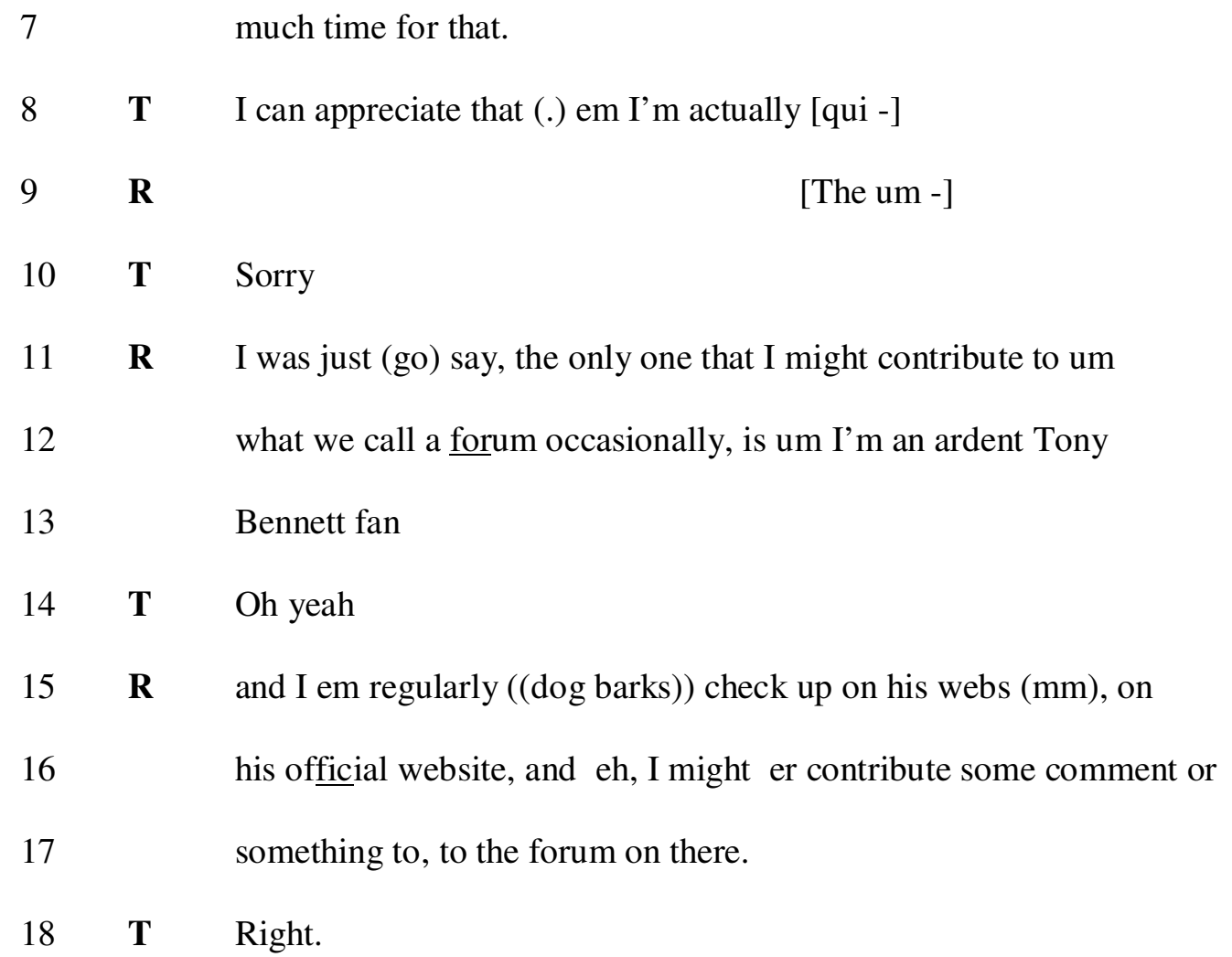

\section{Figure 4: $\quad$ Extract 2}

$1 \quad \mathbf{R}$ Er: looking at what other people are saying gives you (.) sort of an

2 idea as to whether they thought the same way as you did (0.2)

3 whether it was a good or bad concert or (so on) whether it was well

4 played. Er (0.3) I have, I do go to concerts with people, with other

5 people we generally dis- quite often discuss it afterwards

6 T Right

$7 \quad \mathbf{R}$ Ah. I mean I'm not a: ah fanatic for music

$8 \quad \mathbf{T} \quad[(($ laughter $))]$

9 R [I don't, I don't know] the fine details of whether a thing has

10 been well played or so on.

11 T $\quad$ Yeah 
12 R Uh.

\section{Figure 5: $\quad$ Extract 3}

$1 \quad \mathbf{R}$ You're only seeing really one or (.) a very two dimensional picture

2 of them and when you meet them it kind of fills out a bit

$\begin{array}{lll}3 & \mathbf{T} & {[\mathrm{Mmmm}]}\end{array}$

$4 \quad \mathbf{R} \quad$ [It has happened] actually and in fact it was a musical one,

5 when I went to see (.) the Albion Band (0.2) > way back when $<$ em

6 the person that I went to the concert with was completely different

7 from the email persona that he had.

8 T Right

9 R Um (.) which was a disappointment,

$10 \quad \mathbf{T} \quad[(($ laughter $))]$

$11 \mathbf{R}$ [because you know] he made a very thought provoking and, and

12 interesting (.) impression ah in his written form (.) and then I met

13 him and he was a drunkard and (.) quite rude actually: (heh heh)

14 and it didn't quite fit. 